\title{
Sensitivity and Specificity of Urine Trypsinogen 2 Dip Test in Acute Upper Abdominal Pain for the Diagnosis of Acute Pancreatitis
}

\section{Punitkumar Patel ${ }^{1}$, Arun Bahulikar ${ }^{2}$, Nandakumar Beke ${ }^{3}$, Divya Patel ${ }^{4}$ and Deepak Phalgune ${ }^{5 *}$}

${ }^{1}$ Senior resident, Department of Medicine, Poona Hospital and Research Centre,

Pune, India

${ }^{2} \mathrm{HoD}$ and Consultant Physician, Department of Medicine, Poona Hospital and

Research Centre, Pune, India

${ }^{3}$ Consultant Physician, Poona Hospital and Research Centre, Pune, India

${ }^{4} \mathrm{HoD}$, Department of Pathology, Poona Hospital and Research Centre, Pune, India

${ }^{5}$ Research Consultant, Department of Research, Poona Hospital and Research

Centre, Pune, India

*Corresponding Author: Deepak Phalgune, Research Consultant, Department of

Research, Poona Hospital and Research Centre, Pune, India.
Received: November 29, 2021

Published: December 23, 2021

(C) All rights are reserved by Punitkumar

Patel., et al.

\section{Abstract}

Background: There are little data in the literature on the sensitivity of the urine trypsinogen 2 (UT-2) test in the diagnosis of acute pancreatitis, and results have been controversial. Also, studies of UT-2 test in the Indian population are few in number. The aim of the present study was to find the sensitivity and specificity of UT- 2 dipstick test for the diagnosis of acute pancreatitis in acute upper abdominal pain patients.

Material and Methods: One hundred-sixty-six patients aged between 18 and 80 years presenting with acute abdominal pain were included for this cross-sectional observational study. All the patients were tested with UT-2 dipstick test, serum amylase, serum lipase. Ultrasonography or contrast-enhanced computed tomography of abdomen was performed simultaneously. The diagnostic efficacy index such as sensitivity, specificity, positive predictive value, negative predictive value was calculated using the appropriate gold standard.

Results: The sensitivity and specificity of UT-2 dipstick test for detecting acute pancreatitis were $90.7 \%$ and $87.5 \%$ respectively. The sensitivity and specificity of serum amylase for detecting acute pancreatitis were $61.1 \%$ and $100.0 \%$ respectively. The sensitivity and specificity of serum lipase for detecting acute pancreatitis were $81.5 \%$ and $100.0 \%$ respectively.

Conclusions: The UT-2 test had good sensitivity and specificity and can be used reliably for the diagnosis of acute pancreatitis in acute upper abdominal pain.

Keywords: Acute Upper Abdominal Pain; Acute Pancreatitis; Sensitivity; Specificity; Urine Trypsinogen 2 Test

\section{Introduction}

Abdominal pain is one of the most common reasons accounting for about $5.0 \%$ to $10.0 \%$ for an emergency department visit [1]. Most patients with acute pancreatitis have an acute onset of per- sistent, severe epigastric abdominal pain [2].The diagnosis of acute pancreatitis requires the presence of two of the following three criteria: acute onset of persistent, severe, epigastric pain often radiating to the back, elevation in serum lipase or amylase to three times or greater than the upper limit of normal, and characteristic find- 
ings of acute pancreatitis on imaging contrast-enhanced computed tomography (CT), magnetic resonance imaging, or transabdominal ultrasonography (USG) [3].

Serum amylase and lipase historically have been used for the diagnosis of acute pancreatitis. Serum lipase has a sensitivity for acute pancreatitis ranging from $82.0 \%$ to $100.0 \%$ [4]. Serum lipase rises within four to eight hours of the onset of symptoms, peaks at 24 hours, and returns to normal within 8 to 14 days [5]. Serum amylase elevation of greater than three times the upper limit of normal has a sensitivity and specificity of $67.0 \%-83.0 \%$ and $85.0 \%$ $-98.0 \%$ respectively for the diagnosis of acute pancreatitis [5]. Serum amylase rises within 6 to 12 hours of the onset of acute pancreatitis. Amylase has a short half-life of approximately 10 hours and in uncomplicated attacks returns to normal within 3 to 5 days.

There is enough evidence that trypsinogen activation is the earliest step in the commencement of the pathophysiology of acute pancreatitis. Urinary and serum trypsinogen-2 levels are elevated in early acute pancreatitis. In acute pancreatitis, both serum and urinary trypsinogen-2 rise to high levels within a few hours and generally decline in 3 days [6]. Urine trypsinogen 2 (UT-2) dipstick test is the point of care test. In the patient with acute upper abdominal pain, the sensitivity and specificity of the UT-2 dipstick test was $73.0 \%$ and $94.0 \%$ respectively [7-11]. The data in the literature on the sensitivity of the UT- 2 test strip in the diagnosis of acute pancreatitis is modest, and results have been controversial. Also, studies of UT- 2 test in the Indian population are few in number. The aim of the present study was to find the sensitivity and specificity of UT- 2 dipstick test for the diagnosis of acute pancreatitis in acute upper abdominal pain patients.

\section{Material and Methods}

This cross-sectional observational study was conducted between April 2019 and October 2020. After approval from the institutional ethics committee (Letter No. RECH/EC/2019-20/0065), a written informed consent was obtained from all the patients prior to enrolment explaining the risks and benefits of the procedure. Patients aged between 18 and 80 years presenting with acute abdominal pain were included. Patients who were diagnosed with chronic pancreatitis, hereditary pancreatitis, cystic fibrosis and pancreatic carcinoma were excluded.

Detailed clinical history and examination findings were noted of each patient. All patients were tested with UT-2 dipstick test, serum amylase, serum lipase, USG abdomen or CT abdomen per- formed simultaneously. UT-2 dipstick test was based on immunochromatography. It involves two monoclonal antibodies to human trypsinogen-2. One is bound to blue latex particles (the detecting label). The other is immobilized on a carrier membrane to catch labeled particles and indicate a positive result. The detection limit of acute pancreatitis test is approximately $50 \mu \mathrm{g} / \mathrm{L}$ of human trypsinogen- 2 in the sample and the results remain positive at least to $100,000 \mu \mathrm{g} / \mathrm{L}$. The test was done by using Actim Pancreatitis rapid test, Medix Biochemica, Kauniainen, Finland. The serum lipase test was conducted by enzymatic neummetal method, on Siemens Dimension ${ }^{\circledR}$ EXL $^{\mathrm{TM}}$ Systems, Siemens Healthcare Diagnostics Inc. Germany and normal values are 73 - 393 units per liter (U/L). The serum amylase test was done by 2 -chloro-p-nitrophenyl- $\alpha$ D-maltotrioside method, on Dimension ${ }^{\circledR}$ EXL $^{\text {TM }}$ Systems, Siemens Healthcare Diagnostics Inc. Germany and normal values are 30$110 \mathrm{U} / \mathrm{L}$.

Acute pancreatitis was defined as the presence of symptoms and serum amylase or serum lipase > 3 upper limit of normal (ULN) or characteristic finding of acute pancreatitis on USG abdomen or CT abdomen [12]. The UT-2 test was done as soon as possible after the collection of the sample. The dipstick was done shortly after its removal from the foil pouch. The yellow dip area was placed into the sample and held until the liquid front was seen entering the result area. The dipstick was removed from the sample and placed horizontally. The result was interpreted as positive as soon as two blue lines became visible in the result area. The negative result was read at 5 minutes. If two blue lines, the test line and the control line appeared, the test result was considered as a positive. If one blue line, the control line appeared, the test result was considered as a negative. If the control line didn't appear, the test was considered invalid.

The primary outcome measure was to find the sensitivity and specificity of UT- 2 dipstick test for the diagnosis of acute pancreatitis, whereas the secondary outcome measure was to compare the sensitivity and specificity of UT- 2 dipstick test with the sensitivity and specificity of serum amylase and serum lipase for the diagnosis of acute pancreatitis.

Abraham P reported that the specificity of UT- 2 dipstick for the diagnosis of acute pancreatitis was 0.95 and the prevalence was 0.56 [7]. The sample size was calculated by a formula $\mathrm{N}$ [13] $=\frac{\mathrm{Z} \alpha{ }^{2} \times S p(1-S p)}{L^{2} \times(1-\text { Prevalence })}$. We have taken $\mathrm{Z}_{\alpha}$ a standard normal variate at $5 \%$ type 1 error as 1.96 . A total sample size of 166 was calculated by the above method. 
Data collected were entered in Excel 2007 and analysis of data was done using Statistical Package for Social Sciences for Windows, Version 20.0 from IBM Corporation, Armonk, NY, USA. The data on categorical variables are shown as $\mathrm{n}$ (\% of cases). The data on continuous variables are presented as mean and standard deviation (SD). The diagnostic efficacy index such as sensitivity, specificity, positive predictive value (PPV) and negative predictive value (NPV) was calculated using the appropriate gold standard. The confidence limit for significance was fixed at $95 \%$ level with a $\mathrm{p}$-value $<0.05$.

\section{Results}

Of 166 patients, 8 (4.8\%), 11 (6.6\%), 59 (35.5\%),30 (18.1\%), 35 (21.1\%), 10 (6.0\%) and $13(7.8 \%)$ were < 20 years, $20-29$ years, 30 - 39 years, 40 - 49 years, 50 - 59 years, 60 - 69 years and $\geq 70$ years respectively. The mean \pm SD of age of patients was $43.5 \pm 14.8$ years. Of 166 patients, 108 (65.1\%) were males and 58 (34.9\%) were females. Of 166 patients, 133 (80.1\%) had serum amylase level < $330 \mathrm{U} / \mathrm{L}$ and $33(19.9 \%)$ had serum amylase level $\geq 330 \mathrm{U} / \mathrm{L}$. Of 166 pateints, $122(73.5 \%)$ had serum lipase level < $1179 \mathrm{U} / \mathrm{L}$ and $44(26.5 \%)$ had serum lipase level $\geq 1179$ U/L. Of 166 patients, 103 (62.0\%) had negative UT-2 dipstick test and 63 (38.0\%) had positive UT-2 dipstick test. Of 166 patients, 4 (2.4\%), 54 (32.5\%), 52 (31.3\%), 11 (6.6\%), 13 $(7.8 \%)$ and $32(19.3 \%)$ had unknown diagnosis, acute pancreatitis, acute gastritis, acute calculus cholecystitis, acute hepatitis and other diagnosis respectively. Of 54 pateints with acute pancreatitis, 28 (51.9\%), 6 (11.1\%), 12 (22.2\%) and 8 (14.8\%) had alcohol related, gall stone induced, unknown and other causes respectively.

Of 33 patients with serum amylase $\geq 330 \mathrm{U} / \mathrm{L}$, all i.e. 33 (100.0\%) had acute pancreatitis. Of 133 patients with serum amylase $<330$ U/L, 21 (15.8\%) had acute pancreatitis (Table 1). The sensitivity, specificity, PPV, NPV and accuracy of serum amylase for detecting the acute pancreatitis was $61.1 \%, 100.0 \%, 100.0 \%, 84.2 \%$ and $87.3 \%$ respectively (Table 2).

\begin{tabular}{|l|c|c|c|}
\hline & \multicolumn{3}{|c|}{ Acute pancreatitis } \\
\hline & Present & Absent & Total \\
\cline { 1 - 4 } Serum amylase & $\mathrm{n}(\%)$ & $\mathrm{n}(\%)$ & $\mathrm{n}(\%)$ \\
\hline Positive ( $\geq 330 \mathrm{U} / \mathrm{L})$ & $33(100.0)$ & $0(0.0)$ & $33(100.0)$ \\
\cline { 1 - 3 } Negative (<330 U/L) & $21(15.8)$ & 112 & $133(100.0)$ \\
& & $(84.2)$ & \\
\cline { 1 - 3 } Total & $54(32.5)$ & $\begin{array}{c}112 \\
(67.5)\end{array}$ & $166(100.0)$ \\
\hline
\end{tabular}

Table 1: Distribution of acute pancreatitis according to levels of serum amylase.

U/L - Units per liter.

\begin{tabular}{|l|c|c|c|c|c|}
\hline & \multicolumn{5}{|c|}{ Diagnostic efficacy indices } \\
\hline & Sensitivity & Specificity & $\begin{array}{c}\text { Positive } \\
\text { predictive } \\
\text { value }\end{array}$ & $\begin{array}{c}\text { Negative } \\
\text { predictive } \\
\text { value }\end{array}$ & Accuracy \\
\hline $\begin{array}{l}\text { Value } \\
\text { in \% }\end{array}$ & 61.1 & 100.0 & 100.0 & 84.2 & 87.3 \\
\hline
\end{tabular}

Table 2: Diagnostic efficacy indices of serum amylase in the diagnosis of acute pancreatitis.

Of 44 patients with serum lipase $\geq 1179$ U/L, all i.e. $44(100.0 \%)$ had acute pancreatitis. Of 122 patients with serum lipase < 1179 U/L, $10(8.2 \%)$ had acute pancreatitis (Table 3). The sensitivity, specificity, PPV, NPV and accuracy of serum lipase for detecting the acute pancreatitis was $81.5 \%$, $100.0 \%, 100.0 \%, 91.8 \%$ and $93.9 \%$ respectively (Table 4 ).

\begin{tabular}{|l|c|c|c|}
\hline & \multicolumn{3}{|c|}{ Acute pancreatitis } \\
\cline { 1 - 4 } & Positive & Negative & Total \\
\cline { 1 - 4 } Serum lipase & $\mathrm{n}(\%)$ & $\mathrm{n}(\%)$ & $\mathrm{n}(\%)$ \\
\cline { 1 - 4 } Positive $(\geq 1179 \mathrm{U} / \mathrm{L})$ & $44(100.0)$ & $0(0.0)$ & $44(100.0)$ \\
\cline { 1 - 4 } Negative $(<1179 \mathrm{U} / \mathrm{L})$ & $10(8.2)$ & $112(91.8)$ & $122(100.0)$ \\
\cline { 1 - 4 } Total & $54(32.5)$ & $112(67.5)$ & $166(100.0)$ \\
\hline
\end{tabular}

Table 3: Distribution of acute pancreatitis according to levels of serum lipase.

U/L - Units per liter.

\begin{tabular}{|l|c|c|c|c|c|}
\hline & \multicolumn{4}{|c|}{ Diagnostic efficacy indices } \\
\hline & Sensitivity & Specificity & $\begin{array}{c}\text { Positive } \\
\text { predictive } \\
\text { value }\end{array}$ & $\begin{array}{c}\text { Negative } \\
\text { predictive } \\
\text { value }\end{array}$ & Accuracy \\
\hline $\begin{array}{l}\text { Value } \\
\text { in \% }\end{array}$ & 81.5 & 100.0 & 100.0 & 91.8 & 93.9 \\
\hline
\end{tabular}

Table 4: Diagnostic efficacy indices of serum lipase in the diagnosis of acute pancreatitis.

Of 63 patients with positive UT-2 dipstick test, 49 (77.8\%) had acute pancreatitis. Of 122 patients with negative UT-2 dipstick test, 5 (4.9\%) had acute pancreatitis (Table 5). The sensitivity, specificity, PPV, NPV and accuracy of Ut-2 dipstick test for detecting the acute pancreatitis was $90.7 \%$, $87.5 \%, 77.8 \%, 95.1 \%$ and $88.5 \%$ respectively (Table 6).

\section{Discussion}

The present study was conducted to evaluate the sensitivity and specificity of UT-2 test for the diagnosis of acute pancreatitis and to compare the 


\begin{tabular}{|l|c|c|c|}
\hline & \multicolumn{3}{|c|}{ Acute pancreatitis } \\
\hline & Positive & Negative & Total \\
\hline $\begin{array}{l}\text { Urine trypsinogen } 2 \\
\text { dip stick test }\end{array}$ & $\mathrm{n}(\%)$ & $\mathrm{n}(\%)$ & $\mathrm{n}(\%)$ \\
\hline Positive & $49(77.8)$ & $14(22.2)$ & $63(100.0)$ \\
\hline Negative & $5(4.9)$ & $98(95.1)$ & $103(100.0)$ \\
\hline Total & $54(32.5)$ & $112(67.5)$ & $166(100.0)$ \\
\hline
\end{tabular}

Table 5: Distribution of acute pancreatitis according to outcome of Urine trypsinogen 2 dip stick test.

\begin{tabular}{|l|c|c|c|c|c|}
\hline & \multicolumn{4}{|c|}{ Diagnostic efficacy indices } \\
\hline & Sensitivity & Specificity & $\begin{array}{c}\text { Positive } \\
\text { predictive } \\
\text { value }\end{array}$ & $\begin{array}{c}\text { Negative } \\
\text { predictive } \\
\text { value }\end{array}$ & Accuracy \\
\hline $\begin{array}{l}\text { Value } \\
\text { in \% }\end{array}$ & 90.7 & 87.5 & 77.8 & 95.1 & 88.5 \\
\hline
\end{tabular}

Table 6: Diagnostic efficacy indices of Urine trypsinogen 2 dip stick test in the diagnosis of acute pancreatitis.

sensitivity and specificity with serum amylase and lipase for the diagnosis of acute pancreatitis in acute upper abdominal pain patients.

In the present study, the sensitivity of UT-2 dipstick test was $90.7 \%$ for the diagnosis of acute pancreatitis, which was higher than the sensitivity of serum amylase $(61.1 \%)$ and lipase (81.5\%). The specificity of UT-2 dipstick test was $87.5 \%$, which was lower than the specificity of serum amylase $(100.0 \%)$ and serum lipase (100\%). UT-2 dipstick test had good sensitivity, so it could be used as a screening test to diagnose acute pancreatitis in acute upper abdominal pain at the emergency department.

In a study by Kemppainen EA., et al. on 447 patients who presented with acute abdominal pain, UT- 2 test had a sensitivity of $94.0 \%$ and specificity of $95.0 \%$ [11]. In the present study, the sensitivity and specificity of UT-2 were lower as compared to the aforesaid study. In a study by Abraham P., et al. on 124 patients in the Indian population who presented with acute abdominal pain, UT-2 test had a sensitivity of 73.9 and specificity of $94.6 \%$ [7]. In the present study, the sensitivity was higher but specificity was lower than the study conducted by Abraham P., et al. This difference may be explained by the time to testing and variance in interpretation of the faint line on UT-2 test strip by a different user. Chen YT., et al. reported that using a cut-off level of $50 \mathrm{mg} / \mathrm{L}$ for urinary trypsinogen-2, the sensitivity and specificity of the UT- 2 test strip for recognition of acute pancreatitis were $89.6 \%$ and
$85.7 \%$ respectively. The study further stated that UT-2 was comparable to serum amylase/lipase when tested in patients who presented within 24 hours of symptoms onset, whereas with delayed testing (day 3 onwards) the accuracy of the test diminished considerably [14].

Studies have reported that the sensitivity of the UT- 2 test strip was around 91\%-96\% [10,11,15,16]. Pezzilli R., et al. studied 30 patients with acute pancreatitis and found that the sensitivity of the UT-2 dipstick test was 53.3\% [17]. In a Finnish study on 525 patients presenting with acute abdominal pain, the UT-2 test had a sensitivity of $96 \%$ and specificity of $92 \%$ [10].

Kyla"npa"a"-Ba"ck M., et al. reported that the UT-2 test strip detected acute pancreatitis more accurately than quantitative serum lipase. The study further reported that the sensitivity of the UT-2 test strip was $93.0 \%$ compared with $55.0 \%$ of serum lipase at the cut-off of 3 times the upper normal limit [16]. Kemppainen EA., et al. demonstrated that the sensitivity of the UT-2 test strip was higher than that of serum amylase ( $94 \%$ vs. $70 \%$ ), using the cut-off level of serum amylase of 3 times the ULN [11].

In previous reports, the specificity of the UT- 2 test strip was around 90\%-100\% for diagnosing acute pancreatitis [11,15-17]. Chen YT., et al. reported that the specificity of the UT-2 test strip was $85.7 \%$ [14]. The specificity of the UT-2 test strip in the present study was $87.5 \%$.

In the present study, we did not control for the time of UT-2 testing relative to the duration of symptoms. In the present study, $14(22.2 \%)$ false-positive results with UT-2 dipstick test were observed. Kemppainen EA., et al. reported that the false-positive results in patients with abdominal pain who may in some instances have reflected subclinical pancreatic irritation or tumor-derived trypsinogen-2 [11]. UT-2 dipstick is non-invasive, rapid, point of care test. It can be used in healthcare units lacking laboratory facilities.

Potential limitations of the study merit consideration. This study is mainly limited by a small sample size and single centre design, which increases the risk of type II error. Therefore, these findings should be considered hypothesis-generating and need to be confirmed in a larger population. In the present study, we did not control for the time of UT- 2 testing relative to the duration of symptoms. Multicentric studies with a large sample size 
should be undertaken to substantiate the research findings described in this paper.

\section{Conclusions}

The sensitivity and specificity of UT-2 dipstick test for detecting acute pancreatitis were $90.7 \%$ and $87.5 \%$ respectively. The sensitivity and specificity of serum amylase for detecting acute pancreatitis were $61.1 \%$ and $100.0 \%$ respectively. The sensitivity and specificity of serum lipase for detecting acute pancreatitis were $81.5 \%$ and $100.0 \%$ respectively.

\section{Conflict of Interest}

Dr. Punitkumar Patel, Dr. Arun Bahulikar Dr. Nandakumar Beke, Dr. Divya Patel and Dr. Deepak Phalgune declare that they have no conflict of interest.

The manuscript has been read and approved by all the authors, that the requirements for authorship as stated earlier in this document have been met, and that each author believes that the manuscript represents honest work.

\section{Bibliography}

1. Kamin RA., et al. "Pearls and pitfalls in the emergency department evaluation of abdominal pain". Emergency Medicine Clinics of North America 21.1 (2003): 61-72.

2. Swaroop VS., et al. "Severe acute pancreatitis". JAMA 291.23 (2004): 2865-2868.

3. Cochior D., et al. "Clinical importance of the determinantbased classification of acute pancreatitis severity". Chirurgia (Bucur) 108.5 (2013): 631-642.

4. Yadav D., et al. "A critical evaluation of laboratory tests in acute pancreatitis". American Journal of Gastroenterology 97.6 (2002): 1309-1318.

5. Frank B and Gottlieb K. "Amylase normal, lipase elevated: is it pancreatitis? a case series and review of the literature". American Journal of Gastroenterology 94.2 (1999): 463-469.

6. Jang T., et al. "Point-of-care urine trypsinogen testing for the diagnosis of pancreatitis". Academic Emergency Medicine 14.1 (2007): 29-34.

7. Abraham P. "Point-of-care urine trypsinogen-2 test for diagnosis of acute pancreatitis". Journal of the Association of Physicians of India 59 (2011): 231-232.

8. Mayumi T., et al. "Validity of the urinary trypsinogen-2 test in the diagnosis of acute pancreatitis". Pancreas 41.6 (2012): 869-875.
9. Kemppainen E., et al. "Urinary trypsinogen-2 test strip in detecting ERCP-induced pancreatitis". Endoscopy 29.4 (1997): 247-251.

10. Kylänpää-Bäck M., et al. "Reliable screening for acute pancreatitis with rapid urine trypsinogen-2 test strip". British Journal of Surgery 87.1 (2000): 49-52.

11. Kemppainen EA., et al. "Rapid measurement of urinary trypsinogen-2 as a screening test for acute pancreatitis". The New England Journal of Medicine 336.25 (1997): 1788-1793.

12. Banks PA and Freeman ML. "Practice guidelines in acute pancreatitis. Practice Parameters Committee of the American College of Gastroenterology". American Journal of Gastroenterology 101 (2006): 2379-2400.

13. Malhotra RK and Indrayan A. "A simple nomogram for sample size for estimating sensitivity and specificity of medical tests". Indian Journal of Ophthalmology 58.6 (2010): 519-522.

14. Chen YT., et al. "Rapid urinary trypsinogen-2 test strip in the diagnosis of acute pancreatitis". Pancreas 30.3 (2005): 243247.

15. Hedstro"m J., et al. "Urinary trypsinogen-2 test strip for acute pancreatitis". Lancet 347 (1996): 729-731.

16. Kyla"npa"a"-Ba"ck ML., et al. "Comparison of urine trypsinogen-2 test strip with serum lipase in the diagnosis of acute pancreatitis". Hepatogastroenterology 49 (2002): 11301134.

17. Pezzilli R., et al. "Time-course and clinical value of the urine trypsinogen-2 dipstick test in acute pancreatitis". European Journal of Gastroenterology and Hepatology 13 (2001): 269274.

\section{Assets from publication with us}

- Prompt Acknowledgement after receiving the article

- Thorough Double blinded peer review

- Rapid Publication

- Issue of Publication Certificate

- High visibility of your Published work

Website: www.actascientific.com/

Submit Article: www.actascientific.com/submission.php Email us: editor@actascientific.com

Contact us: +919182824667 